Check for updates

Cite this: RSC Adv., 2017, 7, 45733

Received 29th August 2017

Accepted 16th September 2017

DOI: 10.1039/c7ra09602j

rsc.li/rsc-advances

\section{Prealamethicin F50 and related peptaibols from Trichoderma arundinaceum: validation of their authenticity via in situ chemical analysis $\uparrow$}

\author{
José Rivera-Chávez, ${ }^{a}$ Huzefa A. Raja, ${ }^{a}$ Tyler N. Graf, ${ }^{a}$ Jacklyn M. Gallagher, ${ }^{a}$ \\ Prashant Metri, ${ }^{b}$ Ding Xue, ${ }^{b}$ Cedric J. Pearce ${ }^{c}$ and Nicholas H. Oberlies (D) *a
}

In the field of natural products chemistry, a common question pertains to the authenticity of an isolated compound, i.e. are the interesting side chains biosynthesized naturally or an artefact of the isolation/ purification processes? The droplet-liquid microjunction-surface sampling probe (droplet-LMJ-SSP) coupled to a hyphenated system (UPLC-UV-HRESIMS) empowers the analysis of natural product sources in situ, providing data on the biosynthetic timing and spatial distribution of secondary metabolites. In this study the droplet-LMJ-SSP was utilized to validate the authenticity of two new peptaibols (2 and 3) as biosynthesized secondary metabolites, even though both of them had structural features that could be perceived as artefacts. Compounds 2 and 3 were isolated from the scaled up fermentation of Trichoderma arundinaceum (strain MSX70741), along with a new member of the trichobrevin BIII complex (1), and four known compounds (4-7). The structures of the isolates were established using a set of spectroscopic and spectrometric methods, and their absolute configurations were determined by Marfey's analysis. The cytotoxic activity of compounds 1, 3, 4 and 6 was evaluated against a panel of cancer cell lines, where cytotoxic activity in the single digit $\mu \mathrm{M}$ range was observed.

\section{Introduction}

Fungi are a rich source of bioactive secondary metabolites with therapeutic activities. ${ }^{1-3}$ The recent estimates for fungal biodiversity range from 2.2 to 3.8 million species; ${ }^{4}$ however, only a fraction of these fungi ( 135000 species) have been taxonomically characterized and an even smaller percentage examined chemically. ${ }^{5}$ Thus, our understanding of the chemical diversity and pharmacological applications of most fungi is still quite limited. Amongst the well-studied fungi, Trichoderma species are known for their ability to produce bioactive secondary metabolites, including polyketides, alkaloids, terpenoids, non-ribosomally biosynthesized peptides (NRPs), and metabolites of mixed biogenesis. ${ }^{6-8}$ Between the NRPs, peptaibols represent the largest group, with more than 1000 compounds reported to date. ${ }^{9}$ These molecules, typically composed of 5-20 amino acid residues, are characterized by a high content of $\alpha$-aminoisobutyric acid (Aib), an acylated $\mathrm{N}$ -

${ }^{a}$ Department of Chemistry and Biochemistry, University of North Carolina at Greensboro, Greensboro, NC 27402, USA. E-mail: nicholas_oberlies.uncg.edu

${ }^{b}$ Department of Molecular, Cellular and Developmental Biology, University of Colorado, Boulder, CO 80309, USA

'Mycosynthetix, Inc., Hillsborough, NC 27278, USA

$\dagger$ Electronic supplementary information (ESI) available: 1D and 2D NMR data for compounds 1-3. Mass spectrometry analysis for compounds 1-3. Marfey's analysis for compounds $\mathbf{1}$ and $\mathbf{3}$. Tabulated NMR data for compounds 2-4. See DOI: $10.1039 / \mathrm{c} 7 \mathrm{ra0} 0602 \mathrm{j}$ terminus, and a C-terminus that may consist of a free or methoxy substituted 2-amino alcohol, amine, amide, free amino acid or sugar alcohol. ${ }^{\mathbf{1 0 - 1 4}}$

When working on a well-studied structural class, it is relatively easy to pose questions about the biosynthetic authenticity of a new analogue. Artefacts of the isolation process are a well accepted problem. ${ }^{\mathbf{1 5 - 1 7}}$ In addition to adding some confusion to the natural products literature, the biosynthetic authenticity of a compound can be important when considering how certain compounds either support or refute a biosynthetic pathway. In this context, there is value to the development of strategies to either authenticate or invalidate isolated compounds as true secondary metabolites.

Herein, we communicate the application of the recently described droplet-liquid microjunction-surface sampling probe (droplet-LMJ-SSP), which was coupled to a UPLC chromatographic system and paired with both UV and HRESIMS detectors, ${ }^{18}$ to validate the biosynthetic authenticity of fungal secondary metabolites. The droplet-LMJ-SSP is a manually controlled surface sampling tool that performs a microextraction on the culture surface. The droplet-LMJ-SSP has been used in various types of analysis of fungal cultures, including the in situ scouting and identification of peptaibols $^{19}{ }^{19}$ dereplication ${ }^{18}$ and mapping of the spatial and temporal distribution of fungal metabolites, ${ }^{\mathbf{2 0 , 2 1}}$ and to monitor the biosynthesis of targeted non-natural natural products. ${ }^{22}$ 


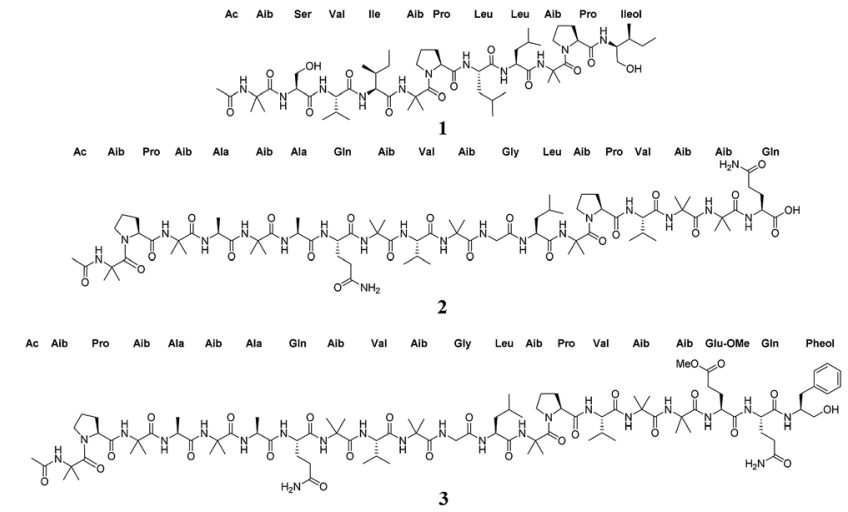

Fig. 1 Structures of compound 1-3.

As part of our ongoing research to discover new anticancer leads from filamentous fungi, ${ }^{23-27}$ Trichoderma arundinaceum strain MSX70741, ${ }^{10}$ a well-known peptaibols producer from the Mycosynthetix library (with more than 55000 fungal accessions $^{28}$ ) was reinvestigated. Consequently, the scaled up culture of strain MSX70741 on rice led to the isolation of three new peptaibols (1-3, Fig. 1), together with the four known compounds alamethicin F50 (4), alamethicin II (5), atroviridin J (6), and trichobranchin D-I (7). ${ }^{10}$ The structures of the isolates were established using a set of spectroscopic (1D and 2D NMR) and spectrometric (HRESIMS/MS ${ }^{n}$ ) techniques. The absolute configurations of these isolates were determined by Marfey's analysis. ${ }^{10,29}$ The cytotoxic activities of compounds 1, 3, 4 and 6 were evaluated in an MTT assay against a panel of human cancer cell lines: HCT 116 (colorectal carcinoma), DLD-1, HT-29, and SW948 (colorectal adenocarcinomas), Hep-G2, and Huh-7 (hepatocellular carcinomas), and HeLa (adenocarcinoma). ${ }^{30}$ The evaluated compounds displayed cytotoxic activities with $\mathrm{IC}_{50}$ values in the single digit $\mu \mathrm{M}$ range. Finally, in situ analysis of the cultures of MSX70741 cultured on potatodextrose-agar (PDA) confirmed the authenticity of the compounds as natural products, discarding the possibility of artefacts of the isolation/purification process.

\section{Results and discussion}

\section{Structure elucidation}

Previous studies on Trichoderma arundinaceum strain MSX70741 stimulated this project, ${ }^{10}$ largely to amplify the supply of key peptaibols for pharmacological assays, as will be reported in the future. Thus, to increase the supply of those peptaibols, four large scale cultures were set up, extracted with $1: 1 \mathrm{CHCl}_{3}-\mathrm{MeOH}$ and partitioned with $4: 1: 5 \mathrm{CHCl}_{3} / \mathrm{MeOH} /$ $\mathrm{H}_{2} \mathrm{O}^{25,26,31}$ The pooled organic soluble extract was then fractionated using normal phase flash chromatography to yield five fractions. Further purification of the fraction that eluted with $100 \% \mathrm{MeOH}$ employing reverse phase flash chromatography, followed by preparative and semi-preparative HPLC, led to the isolation of three new metabolites (trichobrevin BIII-D, prealamethicin F50, and $\mathrm{Glu}(\mathrm{OMe})^{\mathbf{1 8}}$-alamethicin F50, 1-3, respectively) (Fig. 1), along with multi-mg to hundred-mg samples of the known peptaibols, alamethicin F50 (4), alamethicin II (5), atroviridin J (6), and trichobranchin D-I (7).

Compounds 1 and 7 were isolated as white amorphous powders, and their molecular formulae were determined to be $\mathrm{C}_{56} \mathrm{H}_{99} \mathrm{~N}_{11} \mathrm{O}_{13}$ and $\mathrm{C}_{55} \mathrm{H}_{97} \mathrm{~N}_{11} \mathrm{O}_{13}$ on the basis of HRESIMS data $(\mathrm{m} / \mathrm{z}) 1134.7496[\mathrm{M}+\mathrm{H}]^{+}$, and $1120.7343[\mathrm{M}+\mathrm{H}]^{+}$, respectively (calc. for $\mathrm{C}_{56} \mathrm{H}_{100} \mathrm{~N}_{11} \mathrm{O}_{13}$ and $\mathrm{C}_{55} \mathrm{H}_{98} \mathrm{~N}_{11} \mathrm{O}_{13}$ ). In combination with NMR studies, these data indicated 13 degrees of unsaturation for both compounds. Literature searches based on molecular formulae and exact masses in the Dictionary of Natural Products and Peptaibiotics databases indicated that compound 7 was the known peptaibol trichobranchin D-I, previously isolated by Ayers et al., ${ }^{\mathbf{1 0}}$ while $\mathbf{1}$ was closely related to the trichobrevin subclass of peptaibols. The amino acid sequence of compound $\mathbf{1}$ was established on the basis of HRESIMS/MS data. For example, the full scan spectrum showed characteristic ions at $m / z 1134.7506[\mathrm{M}+\mathrm{H}]^{+}, 920.5819\left(\mathrm{~b}_{9}{ }^{+}, \mathrm{N}-\right.$ terminal fragment), $512.3082\left(\mathrm{~b}_{5}^{+}\right), 623.4493\left(\mathrm{y}_{6}^{+}\right.$, C-terminal fragment) and 215.1754 $\left(\mathrm{y}_{2}^{+}\right)$, all fragments generated by cleavage of the labile bonds between $\mathrm{Aib}^{5}-$ Pro $^{6}$ and Aib $^{9}-$ Pro $^{10}$ (Fig. 2) ${ }^{28}$ Further fragmentation of the ion $\mathrm{b}_{5}{ }^{+}$generated a series of $\mathrm{b}^{+}$ions $\left(\mathrm{Ac}^{-} \mathrm{b}_{1}{ }^{+}-\mathrm{b}_{4}{ }^{+} ; m / z=128.0709,215.1014,314.1720\right.$, and 427.2575 , respectively), providing information about the successive losses of $\mathrm{Aib}^{5} \mathrm{Lxx}^{4}$ (Leu or Ile), $\mathrm{Vxx}^{3}$ (Val or Iva), and $\operatorname{Ser}^{2}$ (Fig. 2). HRESIMS/MS of the C-terminal fragment $\mathrm{y}_{6}{ }^{+}$yielded a series of ions corresponding to the loss of the fragment $\mathrm{y}_{2}{ }^{+}$ $(m / z=409.2804)$, Aib9 $(m / z=324.2305)$, and $\operatorname{Lxx}^{8}(\mathrm{~m} / z=$ 211.1445), the last accounting for the molecular formula $\mathrm{C}_{11} \mathrm{H}_{19} \mathrm{~N}_{2} \mathrm{O}_{2}$ and corresponding with a b fragment constituted

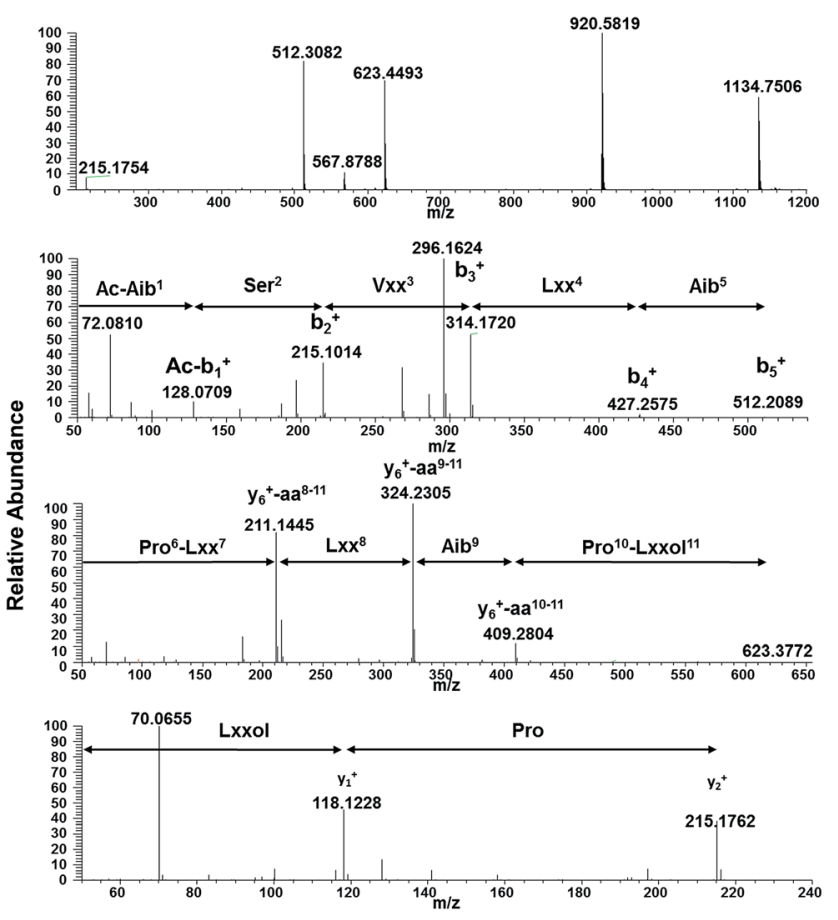

Fig. 2 Positive HRESIMS of compound 1. (A) Full scan showing in source fragmentation, (B-D) HRESIMS/MSn of fragments $b_{5}{ }^{+}, \mathrm{y}_{6}{ }^{+}$and $\mathrm{y}_{2}{ }^{+}$, respectively. 
by Pro and Lxx (Fig. 2). Finally, $\mathrm{MS}^{3}$ of fragment $\mathrm{y}_{2}{ }^{+}$confirmed the presence of Lxxol (Leuol or Ileol) as the C-terminal amino acid by generation of the $\mathrm{y}_{1}{ }^{+}$fragment at $\mathrm{m} / \mathrm{z}=118.1228$, consistent with the formula $\mathrm{C}_{6} \mathrm{H}_{16} \mathrm{NO}$. In view of the data obtained from mass spectrometry, the putative amino acid sequence of compound 1 was Ac-Aib ${ }^{1}-\mathrm{Ser}^{2}-\mathrm{Vxx}^{3}-\mathrm{Lxx}^{4}-\mathrm{Aib}^{5}-$ Pro $^{6}-\mathrm{Lxx}^{7}-\mathrm{Lxx}^{8}-\mathrm{Aib}^{9}-\mathrm{Pro}^{10}{ }^{10} \mathrm{Lxxol}^{11}$

Based upon a detailed search in the Peptaibiotics Database (https://peptaibiotics-database.boku.ac.at), which contains 1350 entries, including over 980 peptaibols, the putative amino acid arrangement of compound 1 resembled the structure of the trichobrevin BIII complex, a family of three compounds identified by HPLC-Ion-Trap-ESIMS in the extract of some strains of
Trichoderma brevicompactum. ${ }^{32}$ Members of the trichobrevin BIII complex share the amino acid sequence Ac-Aib ${ }^{1}-\mathrm{Ser}^{2}-\mathrm{Vxx}^{3}-$ $\mathrm{Lxx}^{4}-\mathrm{Aib}^{5}-\mathrm{PrO}^{6}-\mathrm{Lxx}^{7}-\mathrm{Lxx}^{8}-\mathrm{Aib}^{9}-\mathrm{Pro}^{10}-\mathrm{Lxxol}^{11}{ }^{11}$ however, in the study published by Degenkolb in 2006, the unambiguous identity of Vxx, ${ }^{3}$ Lxx, ${ }^{4}$ Lxx, ${ }^{7}$ Lxx $^{8}{ }^{8}$ and Lxxol $^{11}$ was not established. ${ }^{32}$ In this communication we report the isolation and structural elucidation of a member of this family, which was assigned the trivial name trichobrevin BIII-D (1). The planar structure of compound 1 was established based on exhaustive interpretation of $1 \mathrm{D}$ and $2 \mathrm{D}$ NMR data, and the absolute configuration of the individual amino acids was established from the complete acid hydrolysis and chemical derivatization with Marfey's reagent, followed by UPLC-UV analysis.

Table 1 NMR spectroscopic data for compound 1 (700 and $175 \mathrm{MHz},{ }^{1} \mathrm{H}$ and ${ }^{13} \mathrm{C}$, respectively) in DMSO- $d_{6}$

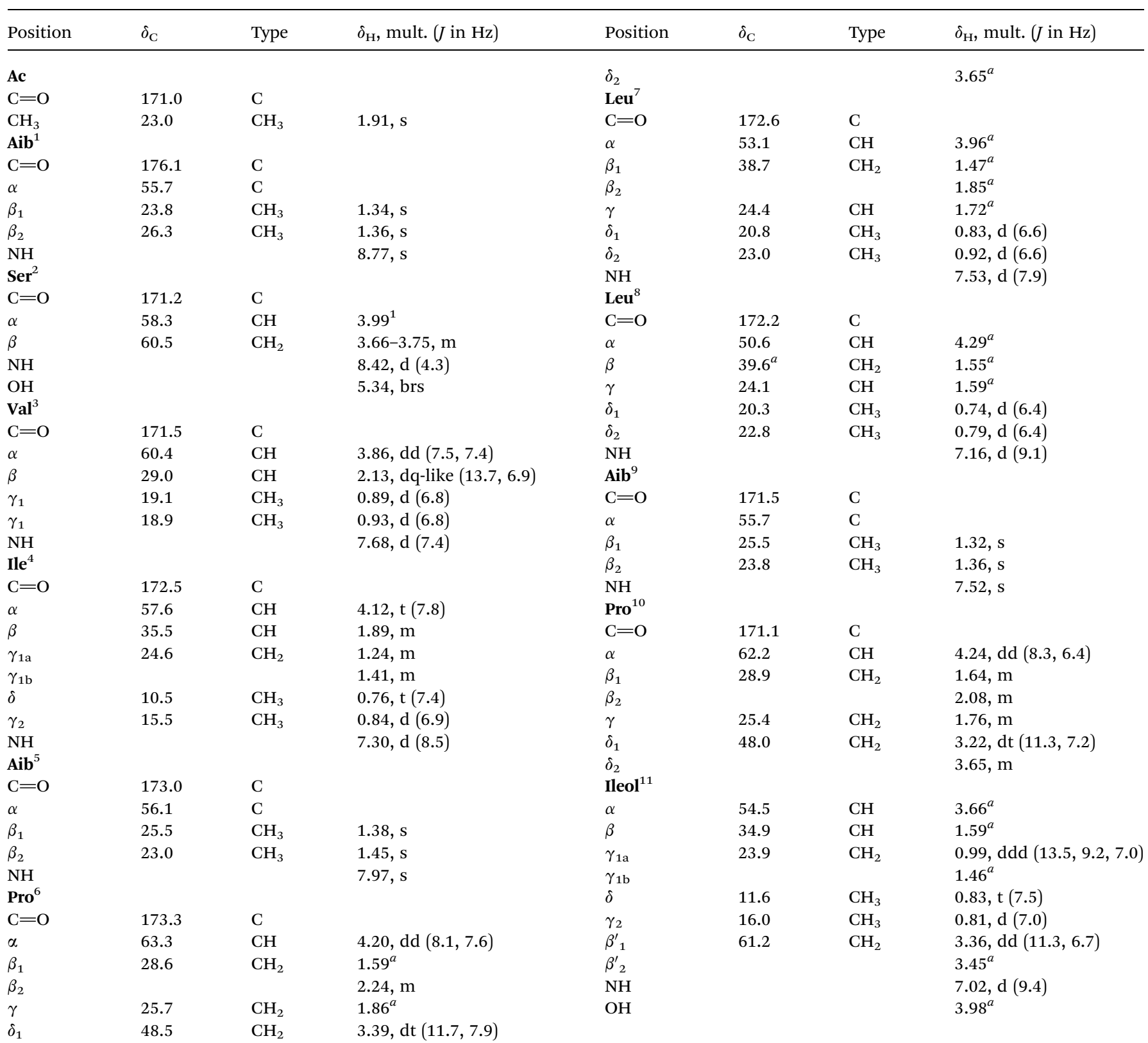

${ }^{a}$ Overlapping signals; chemical shifts were determined from ${ }^{1} \mathrm{H}^{13} \mathrm{C}$ HSQC correlations. 
In brief, the ${ }^{1} \mathrm{H}-\mathrm{NMR}$ of 1 recorded in DMSO- $d_{6}$ exhibited resonances for nine exchangeable protons between $\delta_{\mathrm{H}} 7.02-$ $8.77 \mathrm{ppm}$ (showed by recording the spectra in $\mathrm{MeOH}-d_{3}$ ), signals among $\delta_{\mathrm{H}} 3.22-4.29 \mathrm{ppm}$ belonging to the $\alpha-\mathrm{H}^{\prime} \mathrm{s}$, six singlet signals among $\delta_{\mathrm{H}} 1.32-1.45 \mathrm{ppm}$, attributed to $\mathrm{Aib},{ }^{1} \mathrm{Aib}^{5}$ and Aib, ${ }^{9}$ several doublets ascribed to $\mathrm{Val},{ }^{3} \mathrm{Leu},{ }^{7} \mathrm{Leu},{ }^{8}$ and two triplets at $\delta_{\mathrm{H}} 0.76(J=7.4 \mathrm{~Hz})$, and $\delta_{\mathrm{H}} 0.83(J=7.5 \mathrm{~Hz})$, which were unambiguously assigned to Ile $^{4}$ and Ileol, ${ }^{11}$ respectively. In addition, the presence of a sharp singlet at $\delta_{\mathrm{H}} 1.91 \mathrm{ppm}$ in the ${ }^{1} \mathrm{H}$ NMR spectrum of $\mathbf{1}$ confirmed the presence of an acetylated $\mathrm{N}$-terminal residue (Table 1 ). The ${ }^{13} \mathrm{C}$-NMR spectrum displayed 11 signals between $\delta_{\mathrm{C}}$ 171.0-176.1 ppm assigned to amide carbonyl groups, 15 signals ranging $\delta_{\mathrm{C}} 48-70 \mathrm{ppm}$, and several resonances in the alkyl region. ${ }^{\mathbf{2 8 , 3 3 , 3 4}}$ Interpretation of the 2D-NMR data $\left({ }^{1} \mathrm{H}-{ }^{1} \mathrm{H}\right.$ TOCSY, ${ }^{1} \mathrm{H}-{ }^{1} \mathrm{H}$ COSY, ${ }^{1} \mathrm{H}_{-}-{ }^{13} \mathrm{C}$ HSQC and $\left.{ }^{1} \mathrm{H}^{1}{ }^{13} \mathrm{C} \mathrm{HMBC}\right)$, in particular TOCSY, permitted the assembly of each amino acid through the total spin correlations observed. NOESY correlations of the amide NH's protons with their corresponding neighbouring amino acids, along with HMBC cross peaks of the amide protons through ${ }^{2} J_{\mathrm{CH}}$ with their $i-1$ carbonyl group, and $\alpha \mathrm{C}$, and ${ }^{3} J_{\mathrm{CH}}$ of the $\alpha \mathrm{H}$ 's with the $i$ carbonyl group (Fig. 3), confirmed the sequence of 1 as shown. ${ }^{34}$

The absolute configuration of the individual amino acids in compound 1 was established using a 10 min Marfey's-UPLC-UV method. ${ }^{29}$ The general procedure started with the acid hydrolysis of $\mathbf{1}$, followed by derivatization of the hydrolysate under alkaline conditions with $N_{\alpha}$-(2,4-dinitro-5-fluorophenyl)-L-alaninamide (L-FDAA, Marfey's reagent), followed by UPLC-UV analysis at $340 \mathrm{~nm}$. Finally, the UPLC retention times of the derivatized amino acids in $\mathbf{1}$ were compared with those of derivatized L and D standards for each amino acid (Fig. S7 $\dagger$ ). ${ }^{10}$ Thus the unambiguous structure of compound 1 was assigned as $\quad \mathrm{Ac}^{-\mathrm{Aib}^{1}-\mathrm{L}-\mathrm{Ser}^{2}-\mathrm{L}-\mathrm{Val}^{3} \text {-L-Ile }}{ }^{4}-\mathrm{Aib}^{5}$-L-Pro ${ }^{6}-\mathrm{L}^{-} \mathrm{Leu}^{7}-\mathrm{L}^{-} \mathrm{Leu}^{8}-\mathrm{Aib}^{9}-\mathrm{L}-$ Pro $^{10}{ }^{1-}$-Ileol ${ }^{11}$ and given the trivial name trichobrevin BIII-D. In all of our previous studies on peptaibols, the amino acids were $\mathrm{L},{ }^{\mathbf{1 0}, 28}$ as is typical for this particular class of compounds.

Compound 2 was isolated as a white powder with a molecular formula of $\mathrm{C}_{78} \mathrm{H}_{132} \mathrm{~N}_{20} \mathrm{O}_{22}$ as evidenced by HRESIMS data and analysis of the ${ }^{1} \mathrm{H},{ }^{13} \mathrm{C}$, and edited-HSQC NMR data (Table S1, Fig. S10, S11 and S14†), revealing an index of hydrogen deficiency of 23. The positive full scan MS spectrum of 2 displayed four intense peaks at $m / z 1701.9910\left([\mathrm{M}+\mathrm{H}]^{+}\right.$, calc. for $\left.\mathrm{C}_{78} \mathrm{H}_{133} \mathrm{~N}_{20} \mathrm{O}_{22}, \quad 1701.9897\right), 1189.6946\left(\mathrm{~b}_{13}{ }^{+}\right.$, fragment), $851.4989\left([\mathrm{M}+2 \mathrm{H}]^{2+}\right)$, and $513.3032\left(\mathrm{y}_{5}{ }^{+}\right.$, fragment) (Fig. S8 $\dagger$ ). The composition and absolute configuration of the amino acids was confirmed on the basis of MS $^{2}$ and Marfey's analysis (Fig. 4

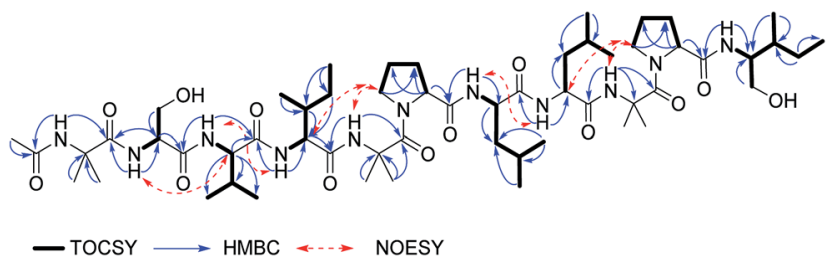

Fig. 3 Selected TOCSY, HMBC and NOESY correlations observed for compound 1. and S9 $\dagger$ ). Thus, the residues were confirmed to be Aib (8), L-Ala (2), L-Pro (2), L-Val (2), L-Gln (2), and L-Leu (1). By acid hydrolysis, the Gln residues in the molecule were converted into $\mathrm{Glu}^{35}$ however, losses of 146.069 and 128.056 a.m.u. in the $\mathrm{MS}^{2}$ spectrum of fragments $\mathrm{y}_{5}{ }^{+}\left(\mathrm{m} / \mathrm{z}\right.$ 513.3032) and $\mathrm{b}_{7}{ }^{+}(\mathrm{m} / \mathrm{z}$ 665.3597), respectively, supported the presence of ${ }_{\mathrm{L}-\mathrm{Gln}}$ (Fig. S9†). ${ }^{11}$ Analysis of $1 \mathrm{D}$ and $2 \mathrm{D}$ NMR data revealed that all the amino acids and connections were the same as those in alamethicin F50 (4). The main differences in 2 compared to 4 were the absence of two signals around at $\delta_{\mathrm{H}} 6.63$ and 7.34, assigned to the $\mathrm{NH}_{2}$ group of $\mathrm{Gln}^{19}$ in 4 , as well as the lack of resonances attributed to the aromatic ring of the $\mathrm{Pheol}^{\mathbf{2 0}}$ moiety

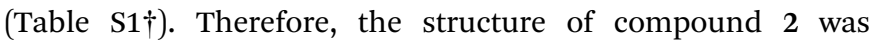
established as Ac-Aib ${ }^{1}-\mathrm{PrO}^{2}-\mathrm{Aib}^{3}-\mathrm{Ala}^{4}-\mathrm{Aib}^{5}-\mathrm{Ala}^{6}-\mathrm{Gln}^{7}-\mathrm{Aib}^{8}$ Val $^{9}-$ Aib $^{10}-$ Gly $^{11}-$ Leu $^{12}-$ Aib $^{13}-$ Pro $^{14}-$ Val $^{15}-$ Aib $^{16}-$ Aib $^{17}-$ Gln, ${ }^{18}$ and assigned the trivial name of prealamethicin F50 (2), since it had the same amino acid sequence minus two C-terminal residues, indicating its close relationship to 4 .

Compound 3 was also isolated as a white powder, and its molecular formula was established as $\mathrm{C}_{93} \mathrm{H}_{152} \mathrm{~N}_{22} \mathrm{O}_{25}$ on the basis of HRESIMS data, which displayed a protonated molecular ion at $m / z$ 1978.1385 $[\mathrm{M}+\mathrm{H}]^{+}$(calc. for $\mathrm{C}_{93} \mathrm{H}_{153} \mathrm{~N}_{22} \mathrm{O}_{25}, \mathrm{~m} / z$ 1978.1371). In source fragmentation of compound 3 generated peaks corresponding to the fragments $\mathrm{b}_{13}{ }^{+}$and $\mathrm{y}_{7}{ }^{+}$at $\mathrm{m} / \mathrm{z}$ 1189.6943 and 789.4504, respectively, along with the $[\mathrm{M}+2 \mathrm{H}]^{2+}$ ion at $m / z$ 989.5727. $\mathrm{MS}^{2}$ of the fragment $\mathrm{b}_{13}{ }^{+}$supported the sequence $\quad \mathrm{Ac}-\mathrm{Aib}^{1}-\mathrm{PrO}^{2}-\mathrm{Aib}^{3}-\mathrm{Ala}^{4}-\mathrm{Aib}^{5}-\mathrm{Ala}^{6}-\mathrm{Gln}^{7}-\mathrm{Aib}^{8}-\mathrm{Val}^{9}-$ $\mathrm{Aib}^{10}-\mathrm{Gly}^{11}-\mathrm{Leu}^{12}-\mathrm{Aib}^{13} \mathrm{MS}^{2}$ of fragment $\mathrm{y}_{7}{ }^{+}$showed the loss of $m / z 279.15987\left(\mathrm{C}_{14} \mathrm{H}_{21} \mathrm{~N}_{3} \mathrm{O}_{3}\right)$, accounting for $\mathrm{Gln}^{19}$ and Pheol. ${ }^{20}$

Further fragmentation of the ion at $\mathrm{m} / \mathrm{z} 510.2917$ gave origin to a peak at $\mathrm{m} / \mathrm{z} 367.2338$, indicating the loss of $\mathrm{m} / \mathrm{z} 143.0581$ $\left(\mathrm{C}_{6} \mathrm{H}_{9} \mathrm{NO}_{3}{ }^{+}\right)$, matching accurately for glutamic acid $\delta$-methyl ester. Thus, $\mathrm{MS}^{2}$ analysis allowed the elucidation of the sequence $\quad \mathrm{Pro}^{14}-\mathrm{Val}^{15}-\mathrm{Aib}^{16}-\mathrm{Aib}^{17}-\mathrm{Glu}-\mathrm{OMe}^{18}-\mathrm{Gln}^{19}-\mathrm{Pheol}^{20}$ (Fig. S16 and S17 $\dagger$ ). ${ }^{1} \mathrm{H},{ }^{13} \mathrm{C}$, and $2 \mathrm{D}-\mathrm{NMR}$ data of compound 3 were similar to those recorded for alamethicin F50 (4) (Table $\mathrm{S} 1 \dagger)$, the main differences being the absence of protons attributed to the $\mathrm{NH}_{2}$ group of $\mathrm{Gln}^{\mathbf{1 8}}$ (Table $\mathrm{S} 1 \dagger$ ), which were replaced by a methoxy group at $\delta_{\mathrm{H}} / \delta_{\mathrm{C}}(3.57 / 51.2)$, showing strong HMBC correlations with the $\delta$ carbon of glutamic acid at $\delta_{\mathrm{C}} 172.8$, supporting the presence of glutamic acid $\delta$-methyl ester. As expected, Marfey's analysis of compound 3 was the same as that

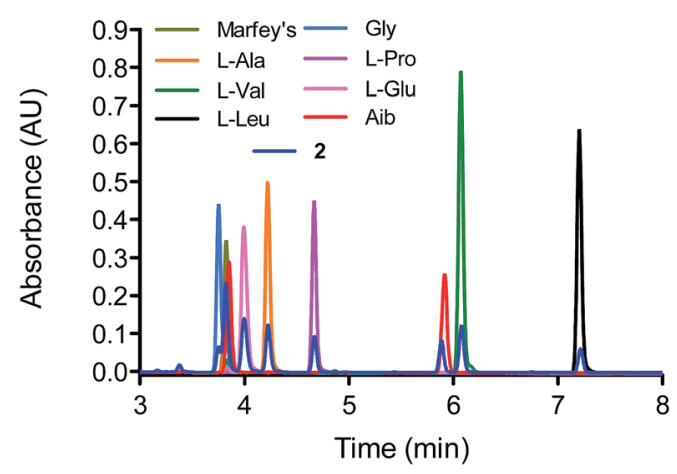

Fig. 4 Marfey's analysis of compound 2. 
for alamethicin F50 (4), allowing the establishment of the absolute configuration of the individual amino acids in compound 3 as L-Pro, L-Ala, L-Gln, L-Val, L-Leu, L-Glu, and L-Pheol (Fig. S24 $\dagger$ ). Thus, compound 3 was characterized as the $\delta$-methyl ester of $\mathrm{Glu}^{\mathbf{1 8}}$ in alamethicin F50, and assigned the name Glu(OMe) ${ }^{18}$-alamethicin F50 (3). This compound was previously obtained via semisynthesis in 1977 by Pandey et al., in a study focused on the structure elucidation of alamethicin I and II, however it is the first report as natural product. ${ }^{36}$

The occurrence of methyl esters of glutamic acid in peptaibols is rare. For example, of the over 1350 peptaibiotics reported in the Peptaibiotics Database, there are just four examples of this subclass of analogues, TA1896, TA1924, TA1910 and TA1924a, all of which are peptaibols with 19 amino acid residues isolated from Trichoderma atroviride by Panizel et al. in $2013 .^{37}$ Thus, the isolation and characterization of compound 3 represents the second report of glutamic acid methyl ester containing peptaibols isolated from nature, and the first belonging to the alamethicin class, the most extensively studied peptaibol. ${ }^{38}$

\section{In situ chemical analysis}

A question that may arise in natural products research pertains to the authenticity of a compound. Is the isolated compound actually biosynthesized by the organism or is it an artefact of the extraction, fractionation and/or the purification processes? Indeed, this question is of particular relevance when isolating compounds of extremely low yield, for instance those in the baseline of a chromatographic run after scaling up an extraction process, and/or when isolating compounds that represent minor derivatives of known compounds, for example methyl esters or close related biosynthetic precursors. This project encompasses all of those aspects. We isolated compounds 2 and 3 as minor side fractions when targeting the large-scale development of compound 4. Moreover, the analogues, while structurally interesting, particularly from a biosynthetic standpoint, represent minor deviations of well-known compounds, in this case the lack of two amino acid residues in 2 or the presence of a glutamic acid methyl ester in $\mathbf{3}$.

Thus, the possibility of isolation of compound 3 as an artefact was discarded based on the outcomes obtained from two experiments. First, alamethicin F50 (4), the compound isolated in high yield from the extract of MSX70741, was stored in $\mathrm{MeOH}$ for one month at room temperature. Afterwards, the ${ }^{1} \mathrm{H}-\mathrm{NMR}$ spectrum was recorded, and the presence of the -OMe singlet at $\delta_{\mathrm{H}} 3.27$ was not observed (data not shown). In addition, in situ UPLC-UV/HRESIMS-MS/MS analysis of the culture of strain
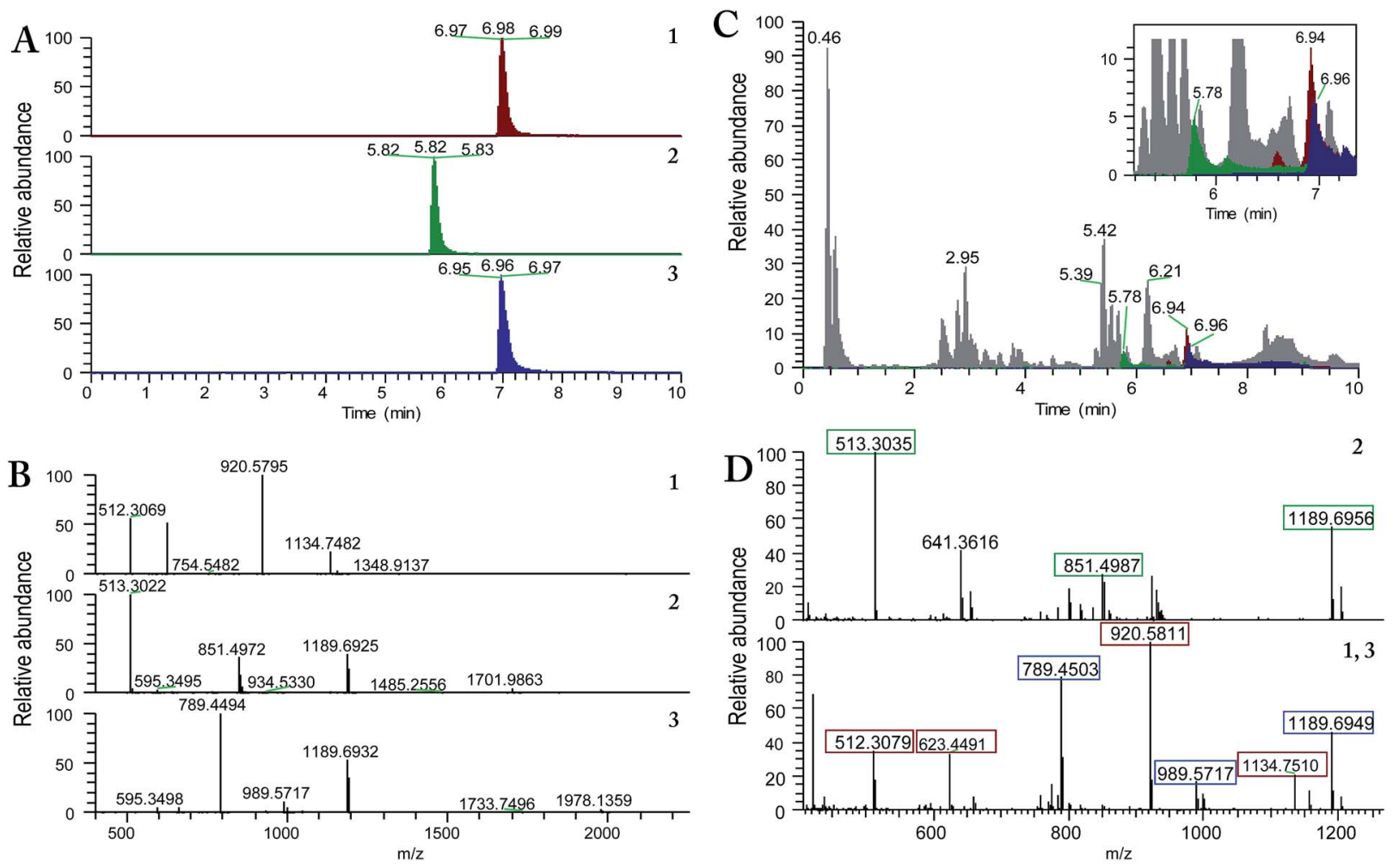

Fig. 5 In situ analysis of Trichoderma arundinaceum strain MSX70741 grown in PDA using a droplet-liquid microjunction-surface sampling probe (droplet-LMJ-SSP) coupled to a hyphenated system (UPLC-UV/HRESIMS-MS/MS). (A) Base peak extracted chromatograms for compounds 1 (maroon), 2 (green) and 3 (blue). (B) Full-scan HRESIMS for compounds 1 (top), 2 (middle), and 3 (bottom). (C) Base peak chromatogram of the in situ analysis of Trichoderma arundinaceum strain MSX70741 (grey); extracted ion chromatograms (XIC) of $\mathrm{m} / \mathrm{z} 920.57$ (1; maroon), $\mathrm{m} / \mathrm{z} 513.30$ (2, green) and $\mathrm{m} / \mathrm{z} 789.44$ (3, blue) matching retention times for compounds 1-3. (D) Full-scan MS at 5.78 (top) and 6.95 min (bottom). Extracted HRESIMS at 5.78 and $6.95 \mathrm{~min}$ matched the retention times and in source fragmentation for compounds 2 (top; in source fragments boxed in green), 1 (bottom, in source fragments boxed in maroon), and 3 (bottom, in source fragments boxed in blue) within \pm 5.0 ppm. Application of this methodology allowed the identification of compounds $1-3$ as natural products, discarding the possibility of artifacts of the isolation process. 
Table 2 Cytotoxic activity of compounds 1, 3, 4 and 6 against a panel of cancer cell lines ${ }^{a}$

\begin{tabular}{lllllllll}
\hline \multicolumn{7}{c}{} & \multicolumn{2}{c}{$\mathrm{IC}_{50}$ values $(\mu \mathrm{M})$} \\
\cline { 2 - 8 } Compounds & HCT-116 & DLD-1 & HT-29 & SW948 & HepG2 & Huh-7 & HeLa \\
\hline $\mathbf{1}$ & 6.8 & $>8$ & 6.7 & $>8$ & $>8$ & $>8$ & $>8$ \\
$\mathbf{3}$ & 2.6 & 6.1 & 3.2 & 4.0 & 6.5 & 3.0 & 2.5 \\
$\mathbf{4}$ & 3.2 & $\mathrm{NT}$ & $\mathrm{NT}$ & $\mathrm{NT}$ & $\mathrm{NT}$ & 6.5 & 5.7 \\
$\mathbf{6}$ & 3.5 & 4.7 & 3.7 & 4.0 & 6.3 & 4.0 & 3.0 \\
${ }^{a}$ & & & & & & &
\end{tabular}

MSX70741 grown in potato-dextrose-agar (PDA) for 21 days, using a droplet-LMJ-SSP, ${ }^{\mathbf{1 8 , 2 0}}$ was used to validate the authenticity of 3 as a true secondary metabolite. The results obtained from this analysis showed a peak matching the retention time and characteristic in-source ion peaks for compound 3, especially the fragment $\mathrm{b}_{13}{ }^{+}$and $\mathrm{y}_{7}{ }^{+}$at $m / z 1189.69$ and 789.45, respectively, along with the $[\mathrm{M}+2 \mathrm{H}]^{2+}$ ion at $m / z 989.57$ (Fig. 5). Similar results were obtained for compounds 1 and 2, validating the authenticity of all the new compounds (1-3) as true fungal metabolites.

\section{Cytotoxic activity}

The activity of compounds 1, 3, 4 and $\mathbf{6}$, were evaluated against a panel of cancer cell lines, including strains HCT 116 (colorectal carcinoma), DLD-1, HT-29, and SW948 (colorectal adenocarcinomas), Hep-G2, and Huh-7 (hepatocellular carcinomas), and HeLa (adenocarcinoma), ${ }^{30}$ using an MTT assay (Table 2). Compound 1 exhibited moderate activity against strains HCT 116 and HT-29 with IC $_{50}$ values of 6.8 and $6.7 \mu \mathrm{M}$, respectively, and no activity against hepatocellular carcinomas and adenocarcinoma cell lines. Glu(OMe) ${ }^{18}$-alamethicin F50 (3) was the most active compound, with $\mathrm{IC}_{50}$ values ranging from 2.5 through $6.5 \mu \mathrm{M}$, and no selectivity against different cell lines (Table 2). The bioactivity results of these compounds correlates with their hydrophobicity and are in harmony with the findings previously reported for peptaibols biosynthesized from 11 amino acids $^{39}$ and alamethicin F50 derivatives. ${ }^{\mathbf{1 0}}$

\section{Experimental section}

\section{General experimental procedures}

NMR experiments were conducted in DMSO- $d_{6}$ or MeOH- $d_{3}$ with presaturation of the $\mathrm{OH}$ peak at $\delta_{\mathrm{H}} 4.92 \mathrm{ppm}$ (wet experiment). NMR instrumentation was an Agilent $700 \mathrm{MHz}$ NMR spectrometer (Agilent Technologies, Inc., Santa Clara, CA, USA) equipped with a cryoprobe, operating at $700 \mathrm{MHz}$ for ${ }^{1} \mathrm{H}$ and $175 \mathrm{MHz}$ for ${ }^{13} \mathrm{C}$. HRESIMS data were obtained using a Thermo QExactive Plus mass spectrometer (ThermoFisher, San Jose, CA, USA) combined with an electrospray ionization source. Dereplication of the fungal culture by in situ sampling was performed using the droplet-LMJ-SSP coupled with a Waters Acquity ultraperformance liquid chromatography (UPLC) system (Waters Corp.) to a Thermo QExactive Plus.
The droplet-LMJ-SSP experiments were carried out using procedures described previously by Sica et al. ${ }^{18}$ Briefly, extractions were performed using Fisher Optima LC/MS grade solvents consisting of $25: 25: 50 \mathrm{MeOH}-$ Dioxane- $\mathrm{H}_{2} \mathrm{O}$. An initial $5 \mu \mathrm{L}$ of solvent were drawn into the syringe. Droplets of $4 \mu \mathrm{L}$ were dispensed onto the surface of the sample at a rate of $2 \mu \mathrm{L} \mathrm{s}^{-1}$, held on the surface for $2 \mathrm{~s}$, and withdrawn back into the syringe at the same rate. This extraction process was repeated in triplicate for a single spot prior to injection into the UPLC-MS system. The HCD fragmentation used a normalized collision energy of 35 for all the compounds to obtain MS/MS data. The UPLC separations were performed using an Acquity BEH $\mathrm{C}_{18}$ column $(50 \mathrm{~mm} \times 2.1 \mathrm{~mm}$, internal diameter, $1.7 \mu \mathrm{m})$ equilibrated at $40{ }^{\circ} \mathrm{C}$ and a flow rate set at $0.3 \mathrm{~mL} \mathrm{~min}{ }^{-1}$. The mobile phase consisted of a linear $\mathrm{MeCN}-\mathrm{H}_{2} \mathrm{O}$ (acidified with $0.1 \%$ formic acid) gradient starting at $15 \% \mathrm{MeCN}$ to $100 \%$ MeCN over $8 \mathrm{~min}$. The mobile phase was held for another $1.5 \mathrm{~min}$ at $100 \% \mathrm{MeCN}$ before returning to the starting conditions. The HPLC separations were performed using a Varian ProStar HPLC system connected to a ProStar 335 photodiode array detector (PDA) with UV detection set at $195 \mathrm{~nm}$ and $210 \mathrm{~nm}$. Preparative HPLC purification of isolated compounds was performed on a Phenomenex Synergi $4 \mu \mathrm{m}$ particle size $\mathrm{C}_{12}$ column $(21 \times 250 \mathrm{~mm})$ at a flow rate of 15.0 or $20.0 \mathrm{~mL} \mathrm{~min}^{-1}$. Semipreparative HPLC was carried out on a Phenomenex Gemini-NX $5 \mu \mathrm{m}$ particle size $\mathrm{C}_{18}$ column $(10 \times 250 \mathrm{~mm})$ or Phenomenex Synergi $4 \mu \mathrm{m}$ particle size $\mathrm{C}_{12}$ column $(10 \times$ $250 \mathrm{~mm}$ ) at $4.6 \mathrm{~mL} \mathrm{~min}^{-1}$. Flash column chromatography was carried out with a Teledyne ISCO Combiflash Rf connected to an ELSD, and with UV detection set at 200-400 nm according with established protocols. ${ }^{\mathbf{1 0 , 2 0 , 2 6 , 2 8 , 3 1 , 4 0}}$

\section{Fungal strain identification}

Fungal strain identification was carried out following the procedures outlined in detail previously. ${ }^{41}$ Also, the ESI $\dagger$ from Rivera-Chávez et al., 2017, ${ }^{22}$ has specific details on the identification of this strain.

\section{Fermentation, extraction and isolation}

The MSX70741 strain (Trichoderma arundinaceum) was isolated in April 1993 by Dr Barry Katz from wood collected in a humid mountain forest (April 1993). ${ }^{10}$ A seed culture of the fungal strain MSX70741 was grown on a malt extract agar slant, and a small piece of agar with mycelium was transferred into YESD media (followed by incubation for 7 days at $22{ }^{\circ} \mathrm{C}$ with agitation at $125 \mathrm{rpm}$ ). The seed culture was subsequently transferred into a $2.8 \mathrm{~L}$ Fernbach flask containing $150 \mathrm{~g}$ of rice and $300 \mathrm{~mL}$ of $\mathrm{H}_{2} \mathrm{O}$ to which was added a vitamin solution. Each flask was incubated at $22{ }^{\circ} \mathrm{C}$ until the cultures showed good growth. To the large scale solid fermentation $(\times 4)$ of MSX70741 was added $500 \mathrm{~mL}$ of $1: 1 \mathrm{CHCl}_{3}-\mathrm{MeOH}$, and the mixtures were shaken for $16 \mathrm{~h}$ at $100 \mathrm{rpm}$ in a reciprocating shaker separately. The solution was filtered, and equal volumes of $\mathrm{H}_{2} \mathrm{O}$ and $\mathrm{CHCl}_{3}$ were added to a final volume of $2 \mathrm{~L}$, the mixture was stirred for $2 \mathrm{~h}$ and then transferred into a separatory funnel. The bottom layer was drawn off and evaporated to dryness. The extract was 
defatted by partitioning between $300 \mathrm{~mL}$ of a mixture of $1: 1$ $\mathrm{MeOH}-\mathrm{MeCN}$ and $300 \mathrm{~mL}$ of hexane in a separatory funnel. The bottom layer was collected and evaporated to dryness. The defatted large scale extract $(7.5 \mathrm{~g})$ was adsorbed onto a minimal amount of Celite 545 (Acros Organics) and mixed using mortar and pestle. This material was fractionated via flash chromatography on a $120 \mathrm{~g}$ RediSep Rf Gold Si-gel column, using a gradient solvent system of hexane- $\mathrm{CHCl}_{3}-\mathrm{MeOH}$ at $85 \mathrm{~mL} \mathrm{m^{-1 }}$ flow rate and 30 column volumes (CV) over $67.7 \mathrm{~min}$, to afford five fractions (F1-F5). Fraction F5 (2.8 g), eluted with $100 \% \mathrm{MeOH}$, was subjected to reverse phase flash chromatography on a $130 \mathrm{~g} \mathrm{C}_{18}$ RediSep column using a gradient solvent system of $\mathrm{MeOH}-\mathrm{H}_{2} \mathrm{O} 20: 80 \rightarrow 100: 0$ over 20 $\mathrm{CV}$ and hold at $100: 0$ for $5 \mathrm{CV}$ at $85 \mathrm{~mL} \mathrm{~min}^{-1}$ flow rate (a total of 25.0 CV over $38.2 \mathrm{~min}$ ), to afford seven fractions $\left(\mathrm{F} 5_{\mathrm{I}}-\mathrm{F} 5_{\mathrm{VII}}\right)$. Part of fraction $\mathrm{F} 5 \mathrm{~V}$ ( $\sim 250 \mathrm{mg})$ was subjected to preparative HPLC using a gradient system initiated with $40: 60 \mathrm{MeCN}-\mathrm{H}_{2} \mathrm{O}(0.1 \%$ formic acid) to $100 \% \mathrm{MeCN}$ over $30 \mathrm{~min}$ at a flow rate of $15.0 \mathrm{~mL} \mathrm{~min}^{-1}$ to generate 16 fractions $\left(\mathrm{F} 5_{\mathrm{V} 1-16}\right)$. Resolution of fraction $\mathrm{F} 5_{\mathrm{V}-4}$ by semipreparative HPLC (Gemini-NX) using an isocratic system of $60: 40 \mathrm{MeCN}-\mathrm{H}_{2} \mathrm{O}(0.1 \%$ formic acid $)$ at $4.6 \mathrm{~mL} \mathrm{~min}{ }^{-1}$ afforded compound 7 ( $\left.3.1 \mathrm{mg}, t_{\mathrm{R}} 14.5 \mathrm{~min}\right)$ and compound 4 ( $2.0 \mathrm{mg}, t_{\mathrm{R}} 17.0$ min). Fraction $\mathrm{F} 5 \mathrm{~V}-7$ was resolved by semipreparative HPLC (Synergi) using an isocratic method of 60 : $40 \mathrm{MeCN}-\mathrm{H}_{2} \mathrm{O}(0.1 \%$ formic acid) to afford compound $2\left(4.3 \mathrm{mg}, t_{\mathrm{R}} 14.0 \mathrm{~min}\right)$. Resolution of fraction $\mathrm{F}_{\mathrm{V}-8}$ using an isocratic method of $60: 40 \mathrm{MeCN}-\mathrm{H}_{2} \mathrm{O}$ (0.1\% formic acid) led to the isolation of $3\left(4.0 \mathrm{mg}, t_{\mathrm{R}} 17.5-20.0\right.$ min). Fractions $\mathrm{F} 5_{\mathrm{I}}$, and $\mathrm{F} 5_{\mathrm{II}}$ were combined and fractionated by preparative HPLC using a gradient system initiated with $40: 60$ $\mathrm{MeCN}-\mathrm{H}_{2} \mathrm{O}$ ( $0.1 \%$ formic acid) to $100 \% \mathrm{MeCN}$ over $30 \mathrm{~min}$ at

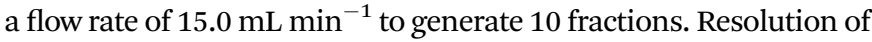
fraction $\mathrm{F}_{\mathrm{I}-\mathrm{II}-3}$ using a gradient method starting at $40: 60 \mathrm{MeCN}-$ $\mathrm{H}_{2} \mathrm{O}(0.1 \%$ formic acid $)$ to $100 \% \mathrm{MeCN}$ over $30 \mathrm{~min}$ at a flow rate of $4.6 \mathrm{~mL} \mathrm{~min} \mathrm{~m}^{-1}$ in a Synergi column led to the isolation of $1(1.2 \mathrm{mg}$, $t_{\mathrm{R}}$ 17.5-20.0 $\mathrm{min}$ ). Compounds 5 and 6 were obtained from fractions $\mathrm{F}_{\mathrm{V}-6}$ and $\mathrm{F} 5_{\mathrm{I}-\mathrm{II}}$, respectively $(5,50.4 \mathrm{mg} ; 6,13.5 \mathrm{mg}$ ), approximately $130 \mathrm{mg}$ more of compound $\mathbf{4}$ were isolated readily from different fractions.

Trichobrenin BIII-D (1). White powder; $[\alpha]_{\mathrm{D}}^{27}=-3.0(c=$ 0.20, MeOH); UV (MeOH) $\lambda_{\max }(\log \varepsilon) 211$ (3.75) nm; ${ }^{1} \mathrm{H}$ NMR (DMSO- $d_{6}, 700 \mathrm{MHz}$ ) and ${ }^{13} \mathrm{C}$ NMR (DMSO- $d_{6}, 175 \mathrm{MHz}$ ), see Table 1; HRESIMS $m / z$ 1134.7506 $[\mathrm{M}+\mathrm{H}]^{+}$; calc. for $\mathrm{C}_{56} \mathrm{H}_{100} \mathrm{~N}_{11} \mathrm{O}_{13}$ 1134.7496.

Prealamethicin F50 (2). White powder; $[\alpha]_{\mathrm{D}}^{27}=-1.0(c=0.10$, $\mathrm{MeOH}) ; \mathrm{UV}(\mathrm{MeOH}) \lambda_{\max }(\log \varepsilon) 212(4.25) \mathrm{nm} ;{ }^{1} \mathrm{H}$ NMR $(\mathrm{MeOH}-$ $\left.d_{3}, 700 \mathrm{MHz}\right)$ and ${ }^{13} \mathrm{C} \mathrm{NMR}\left(\mathrm{MeOH}-d_{3}, 175 \mathrm{MHz}\right)$, see Table S1; $\dagger$ HRESIMS $m / z 1701.9910[\mathrm{M}+\mathrm{H}]^{+}$; calc. for $\mathrm{C}_{78} \mathrm{H}_{132} \mathrm{~N}_{20} \mathrm{O}_{22}$ 1701.9897.

Glu(OMe) ${ }^{18}$-alamethicin F50 (3). White powder; $[\alpha]_{\mathrm{D}}^{27}=-6.0$ $(c=0.27, \mathrm{MeOH}) ; \mathrm{UV}(\mathrm{MeOH}) \lambda_{\max }(\log \varepsilon) 212(3.89) \mathrm{nm} ;{ }^{1} \mathrm{H}$ NMR (DMSO- $d_{6}, 700 \mathrm{MHz}$ ) and ${ }^{13} \mathrm{C}$ NMR (DMSO- $d_{6}, 175 \mathrm{MHz}$ ), see Table S1; $\dagger$ HRESIMS $m / z$ 1978.1337 $[\mathrm{M}+\mathrm{H}]^{+}$; calc. for $\mathrm{C}_{93} \mathrm{H}_{153} \mathrm{~N}_{22} \mathrm{O}_{25}, m / z$ 1978.1371.

\section{Marfey's analysis}

This was carried out as described in detail previously. ${ }^{\mathbf{1 0 , 1 9 , 2 2}}$ Briefly, approximately $0.2 \mathrm{mg}$ of each amino acid standard was weighed into $2 \mathrm{~mL}$ reaction vials. To each standard was added $50 \mu \mathrm{L}$ of $\mathrm{H}_{2} \mathrm{O}, 20 \mu \mathrm{L}$ of $1 \mathrm{M} \mathrm{NaHCO}_{3}$, and $100 \mu \mathrm{L} 1 \%$ Marfey's reagent $\left(N_{\alpha}\right.$-(2,4-dinitro-5-fluorophenyl)-L-alaninamide, Acros Organics) in acetone. The reaction mixtures were agitated at $40{ }^{\circ} \mathrm{C}$ for $1 \mathrm{~h}$. The reactions were stopped by adding $10 \mu \mathrm{L}$ of $2 \mathrm{~N}$ $\mathrm{HCl}$. The product of the reactions was dried under a stream of $\mathrm{N}_{2}$ and dissolved in $\sim 1.7 \mathrm{~mL}$ of $\mathrm{MeOH}$. Each derivatized standard was injected individually $(1.0 \mu \mathrm{L})$ onto the UPLC. The UPLC conditions were $10-70 \% \mathrm{MeOH}$ in $0.1 \%$ of formic acid in water over $10 \mathrm{~min}$ on a $\mathrm{BEH} \mathrm{C}_{18}$ column, and the eluent was monitored at $340 \mathrm{~nm}$.

The digested and derivatized peptaibols were generated using the following procedure: approximately $0.2-0.3 \mathrm{mg}$ of compounds 1-3 were weighed separately into $2 \mathrm{~mL}$ reaction vials, to which was added $0.5 \mathrm{~mL}$ of $6 \mathrm{~N} \mathrm{HCl}$. The compounds were hydrolyzed at $90{ }^{\circ} \mathrm{C}$ for $24 \mathrm{~h}$, and then evaporated under a stream of $\mathrm{N}_{2}$. To each hydrolysis product was then added $25 \mu \mathrm{L} \mathrm{H} \mathrm{H}_{2} \mathrm{O}, 10 \mu \mathrm{L} 1 \mathrm{M} \mathrm{NaHCO}$, and $50 \mu \mathrm{L}$ of $1 \%$ Marfey's reagent in acetone. The reaction mixtures were agitated at $40{ }^{\circ} \mathrm{C}$ for $1 \mathrm{~h}$. The reactions were halted by the addition of $5 \mu \mathrm{L}$ of $2 \mathrm{~N}$ $\mathrm{HCl}$. The mixtures were dried under a stream of $\mathrm{N}_{2}$ and brought up in $\sim 200 \mu \mathrm{L}$ of $\mathrm{MeOH}$ and injected onto the UPLC using the same conditions as for the standards.

\section{Cytotoxicity assay}

Cell culture. Cell-culture reagents, antibiotics and other supplements were purchased from Sigma, USA. Fetal Bovine Serum (FBS, US certified) was from Invitrogen Life Sciences, USA. HCT-116, DLD-1, HT29, SW948, HepG2, Huh-7, HeLa cells were grown in Dulbecco's Modified Eagle's Medium (SigmaAldrich, USA) or RPMI-1640 (with 10\% FBS, 100 units/mL penicillin and $100 \mu \mathrm{g} \mathrm{mL} \mathrm{m}^{-1}$ streptomycin) (Invitrogen Life Sciences, USA). The cells were maintained at $37^{\circ} \mathrm{C}$ in a humidified atmosphere with $5 \% \mathrm{CO}_{2}$. All cell-culture work was performed under aseptic conditions inside a laminar airflow chamber.

Assay. Toxicity of the compounds in different cell lines in the presence of $0.2 \%$ FBS was determined using 3-(4,5dimethylthiazole-2-yl)-2,5-diphenyltetrazolium bromide reduction assay (MTT assay). Compounds were dissolved in DMSO at $10 \mathrm{mg} \mathrm{mL}{ }^{-1}$ concentration and stored at $-20{ }^{\circ} \mathrm{C}$. The dilutions were made in culture medium before treatment. $5 \times 10^{3}$ cells per well was plated in a 96-well plate. After $24 \mathrm{~h}$ of plating, the cells were treated with different concentrations of compounds in triplicates. MTT $\left(20 \mu \mathrm{L}\right.$ of $\left.5 \mathrm{mg} \mathrm{mL}^{-1}\right)$ was added to the cells after $44 \mathrm{~h}$. The medium was removed from the wells $4 \mathrm{~h}$ after MTT addition. $200 \mu \mathrm{L}$ of DMSO were added to dissolve the formazan crystals, and the absorbance was then measured at $570 \mathrm{~nm}$ in an enzyme-linked immunosorbent assay reader. Alamethicin F50 (4) was used as a positive control, as it has been tested extensively in the literature. ${ }^{\mathbf{1 0 , 2 2}}$

\section{Conclusions}

In conclusion, three new peptaibols (1-3) were isolated and characterized from the organic extract of the fungus 
Trichoderma arundinaceum (strain MSX70741). The structures of the isolates were established using high field 1D and 2D NMR $(700 \mathrm{MHz})$ and spectrometric (HRESIMS/MS ${ }^{\mathrm{n}}$ ) techniques, and their absolute configuration determined by Marfey's analysis of the individual amino acids using a 10 min UPLC method. Compound 3 represents the second report of peptaibols containing a $\delta$-methyl ester of glutamic acid. Compounds 1, 3, 4 and 6 were evaluated for their cytotoxicity against a panel of cancer cell lines. Products 3 and $\mathbf{6}$ displayed promising activity with $\mathrm{IC}_{50}$ values in the lower micromolar range. Importantly, in situ UPLC-UV/HRESIMS-MS/MS analysis of the culture of strain MSX70741 grown in potato-dextrose-agar allowed the identification of compounds $\mathbf{2 - 3}$ as natural products, eliminating the possibility of artefacts of the isolation process. This study added another application of the droplet-LMJ-SSP, confirming it as a powerful and effective tool to address some of the common problems and questions in natural products research and drug discovery, such as those regarding the biosynthesis of targeted compounds, chemical ecology (spatial distribution of metabolites) and improving the efficacy of protocols focused on the discovery of new drug leads from nature (dereplication protocols). Finally, this study highlights the benefit of scaling up the fermentation conditions of a targeted microorganism, as doing so often present opportunities to uncover new chemical diversity.

\section{Conflicts of interest}

There are no conflicts to declare.

\section{Acknowledgements}

This research was supported in part by P01 CA125066 from the National Cancer Institute and R01 GM088241 from the National Institute of General Medical Sciences, both part of the National Institutes of Health, Bethesda, MD, USA. Mycology technical support was provided by B. Darveaux (Mycosynthetix). The authors acknowledge the technical assistance of Dr Franklin Moy (the University of North Carolina at Greensboro) for the $700 \mathrm{MHz}$ NMR data. The high-resolution mass spectrometry data were acquired in the Triad Mass Spectrometry Laboratory at the University of North Carolina at Greensboro. We thank Dr Vilmos Kertesz and Gary J. Van Berkel (Mass Spectrometry and Laser Spectroscopy Group, Chemical Sciences Division, Oak Ridge National Laboratory) for inspiration and guidance with the droplet-LMJ-SSP.

\section{References}

1 L. J. Barkal, A. B. Theberge, C.-J. Guo, J. Spraker, L. Rappert, J. Berthier, K. A. Brakke, C. C. C. Wang, D. J. Beebe, N. P. Keller and E. Berthier, Nat. Commun., 2016, 7, DOI: 10.1038/ncomms10610.

2 A. Evidente, A. Kornienko, A. Cimmino, A. Andolfi, F. Lefranc, V. Mathieu and R. Kiss, Nat. Prod. Rep., 2014, 31, 617-627.
3 A. Schueffler and T. Anke, Nat. Prod. Rep., 2014, 31, 14251448.

4 D. L. Hawksworth and R. Lücking, Microbiol. Spectrum, 2017, 5, DOI: 10.1128/microbiolspec.FUNK-0052-2016.

5 D. Hibbett, K. Abarenkov, U. Kõljalg, M. Öpik, B. Chai, J. Cole, Q. Wang, P. Crous, V. Robert, T. Helgason, J. R. Herr, P. Kirk, S. Lueschow, K. O'Donnell, R. H. Nilsson, R. Oono, C. Schoch, C. Smyth, D. M. Walker, A. Porras-Alfaro, J. W. Taylor and D. M. Geiser, Mycologia, 2016, 108, 1049-1068.

6 F. Almassi, E. L. Ghisalberti, M. J. Narbey and K. Sivasithamparam, J. Nat. Prod., 1991, 54, 396-402.

7 P. K. Mukherjee, B. A. Horwitz and C. M. Kenerley, Microbiology, 2012, 158, 35-45.

8 J. L. Reino, R. F. Guerrero, R. Hernández-Galán and I. G. Collado, Phytochem. Rev., 2008, 7, 89-123.

9 N. K. N. Neumann, N. Stoppacher, S. Zeilinger, T. Degenkolb, H. Brückner and R. Schuhmacher, Chem. Biodiversity, 2015, 12, 743-751.

10 S. Ayers, B. M. Ehrmann, A. F. Adcock, D. J. Kroll, E. J. Carcache de Blanco, Q. Shen, S. M. Swanson, J. O. Falkinham, M. C. Wani, S. M. Mitchell, C. J. Pearce and N. H. Oberlies, J. Pept. Sci., 2012, 18, 500-510.

11 T. Degenkolb, A. Berg, W. Gams, B. Schlegel and U. Gräfe, J. Pept. Sci., 2003, 9, 666-678.

12 M. Shi, H.-N. Wang, S.-T. Xie, Y. Luo, C.-Y. Sun, X.-L. Chen and Y.-Z. Zhang, Mol. Cancer, 2010, 9, 1-16.

13 C. Toniolo and H. Brückner, Chem. Biodiversity, 2007, 4, 1021-1022.

14 L. Whitmore, J. K. Chugh, C. F. Snook and B. A. Wallace, J. Pept. Sci., 2003, 9, 663-665.

15 C.-M. Cao, H. Zhang, R. J. Gallagher and B. N. Timmermann, J. Nat. Prod., 2013, 76, 2040-2046.

16 F. Maltese, F. van der Kooy and R. Verpoorte, Nat. Prod. Commun., 2009, 4, 447-454.

17 D. Reimer and C. C. Hughes, J. Nat. Prod., 2017, 80, 126-133. 18 V. P. Sica, H. A. Raja, T. El-Elimat, V. Kertesz, G. J. Van Berkel, C. J. Pearce and N. H. Oberlies, J. Nat. Prod., 2015, 78, 1926-1936.

19 V. P. Sica, E. R. Rees, H. A. Raja, J. Rivera-Chávez, J. E. Burdette, C. J. Pearce and N. H. Oberlies, Phytochemistry, 2017, 143, 45-53.

20 N. D. Paguigan, H. A. Raja, C. S. Day and N. H. Oberlies, Phytochemistry, 2016, 126, 59-65.

21 V. P. Sica, E. R. Rees, E. Tchegnon, R. H. Bardsley, H. A. Raja and N. H. Oberlies, Frontiers in Microbiology, 2016, 7, 544.

22 J. Rivera-Chávez, H. A. Raja, T. N. Graf, J. E. Burdette, C. J. Pearce and N. H. Oberlies, J. Nat. Prod., 2017, 80, 1883-1892.

23 S. Ayers, B. M. Ehrmann, A. F. Adcock, D. J. Kroll, M. C. Wani, C. J. Pearce and N. H. Oberlies, Tetrahedron Lett., 2011, 52, 5733-5735.

24 S. Ayers, T. N. Graf, A. F. Adcock, D. J. Kroll, Q. Shen, S. M. Swanson, S. Matthew, E. J. Carcache de Blanco, M. C. Wani, B. A. Darveaux, C. J. Pearce and N. H. Oberlies, J. Antibiot., 2012, 65, 3-8. 
25 T. El-Elimat, M. Figueroa, H. A. Raja, T. N. Graf, S. M. Swanson, J. O. Falkinham 3rd, M. C. Wani, C. J. Pearce and N. H. Oberlies, Eur. J. Org. Chem., 2015, 2015, 109-121.

26 M. Figueroa, T. N. Graf, S. Ayers, A. F. Adcock, D. J. Kroll, J. Yang, S. M. Swanson, U. Munoz-Acuna, E. J. Carcache de Blanco, R. Agrawal, M. C. Wani, B. A. Darveaux, C. J. Pearce and N. H. Oberlies, J. Antibiot., 2012, 65, 559-564.

27 A. A. Sy-Cordero, M. Figueroa, H. A. Raja, M. E. Meza Aviña, M. P. Croatt, A. F. Adcock, D. J. Kroll, M. C. Wani, C. J. Pearce and N. H. Oberlies, Tetrahedron, 2015, 71, 8899-8904.

28 M. Figueroa, H. Raja, J. O. Falkinham, A. F. Adcock, D. J. Kroll, M. C. Wani, C. J. Pearce and N. H. Oberlies, J. Nat. Prod., 2013, 76, 1007-1015.

29 S. Vijayasarathy, P. Prasad, L. J. Fremlin, R. Ratnayake, A. A. Salim, Z. Khalil and R. J. Capon, J. Nat. Prod., 2016, 79, 421-427.

30 J. Van Meerloo, G. J. L. Kaspers and J. Cloos, in Cancer Cell Culture: Methods and Protocols, ed. A. I. Cree, Humana Press, Totowa, NJ, 2011, DOI: 10.1007/978-1-61779-080-520, pp. 237-245.

31 S. Ayers, T. N. Graf, A. F. Adcock, D. J. Kroll, Q. Shen, S. M. Swanson, M. C. Wani, B. A. Darveaux, C. J. Pearce and N. H. Oberlies, Tetrahedron Lett., 2011, 52, 5128-5130.
32 T. Degenkolb, T. Gräfenhan, H. I. Nirenberg, W. Gams and H. Brückner, J. Agric. Food Chem., 2006, 54, 7047-7061.

33 D. Liu, H. Lin, P. Proksch, X. Tang, Z. Shao and W. Lin, Org. Lett., 2015, 17, 1220-1223.

34 A. Otto, A. Laub, L. Wendt, A. Porzel, J. Schmidt, G. Palfner, J. Becerra, D. Krüger, M. Stadler, L. Wessjohann, B. Westermann and N. Arnold, J. Nat. Prod., 2016, 79, 929938.

35 M. Isaka, S. Palasarn, S. Komwijit, S. Somrithipol and S. Sommai, Tetrahedron Lett., 2014, 55, 469-471.

36 R. C. Pandey, J. C. Cook and K. L. Rinehart, J. Am. Chem. Soc., 1977, 99, 8469-8483.

37 I. Panizel, O. Yarden, M. Ilan and S. Carmeli, Mar. Drugs, 2013, 11, 4937.

38 B. Leitgeb, A. Szekeres, L. Manczinger, C. Vágvölgyi and L. Kredics, Chem. Biodiversity, 2007, 4, 1027-1051.

39 N. Ruiz, G. Wielgosz-Collin, L. Poirier, O. Grovel, K. E. Petit, M. Mohamed-Benkada, T. R. du Pont, J. Bissett, P. Vérité, G. Barnathan and Y. F. Pouchus, Peptides, 2007, 28, 13511358.

40 T. El-Elimat, M. Figueroa, H. A. Raja, T. N. Graf, A. F. Adcock, D. J. Kroll, C. S. Day, M. C. Wani, C. J. Pearce and N. H. Oberlies, J. Nat. Prod., 2013, 76, 382-387.

41 H. A. Raja, A. N. Miller, C. J. Pearce and N. H. Oberlies, J. Nat. Prod., 2017, 80, 756-770. 